\title{
LISTA DE CONTROL PARA UN ADECUADO AGARRE DEL LÁPIZ
}

Checklist for an appropriate pencil grip

Lista de verificação para agarrar corretamente o lápis

\author{
Alejandra Sevilla Valcarce \\ C.R.A. Santa Bárbara - Torre del Bierzo. alejandrasv00@gmail.com
}

\begin{abstract}
Resumen
En esta experiencia se analiza el proceso de evaluación formativa en el trabajo de la motricidad fina en el inicio de la etapa de Educación Infantil, en concreto en relación al agarre del lápiz para el proceso de la escritura. La implicación de las familias y del propio alumnado, a través de un instrumento de evaluación que indica los aspectos a valorar y los niveles de logro por los que puede pasar el alumnado, permite coordinar una línea de retroalimentaciones coherentes a través de la potenciación de la relación familia-escuela. Los resultados han demostrado que, aun con las diferencia iniciales del alumnado por la asistencia previa o no al Centro de Educación Infantil donde se trabajó este aspecto, a mediados de curso éstas habían desaparecido.

Palabras clave: Motricidad fina; agarre del lápiz; evaluación formativa; relación familia-escuela
\end{abstract}

\begin{abstract}
In this experience the process of formative evaluation in the work of the fine motor at the beginning of the infantile stage, in particular in relation to the grasp of the pen for the process of the writing, is analyzed. The involvement of families and the students themselves, through an assessment instrument, that indicates the aspects to be assessed and the levels of achievement that students can pass through, allows a coherent line of feedback to be coordinated through the empowerment of family-school relationship. The results have shown that, even with the initial differences of the students due to the previous attendance or not to the nursery where this aspect was worked, in the middle of the curricula these had disappeared.
\end{abstract}

Keywords: Fine motor skills; Pencil grip; Formative assessment; Family-school relationship 


\section{Resumo}

Nesta experiência o processo de avaliação formativa discutido na obra de habilidades motoras finas no início da fase infantil, particularmente em relação à aderência a caneta para o processo de escrita. O envolvimento das famílias e os próprios alunos, através de um instrumento de avaliação indicando aspectos para níveis de valor e de realização para aqueles que podem passar os estudantes, pode coordenar um feedback linha consistente através da capacitação relação família-escola. Os resultados mostraram que, mesmo com a diferença inicial dos alunos por atendimento prévio ou não para o berçário onde trabalhou este aspecto, em meados da década de Curos tinham desaparecido.

Palavras-chave: motricidade fina; agarre do lápis; avaliação formativa; relação família-escola

\section{Introducción}

El dominio adecuado de nuestro cuerpo nos permite una mejor relación con el medio y con los demás. García y Berruezo (1999) afirman que en Educación Infantil (EI) se deben facilitar y afianzar los logros que posibilitan la maduración referente al control del cuerpo. En concreto, las acciones relacionadas con la motricidad fina son innumerables, aunque en este caso nos centraremos en la evolución del agarre del lápiz. Observar los diferentes procesos que sigue el niño para tener una buena escritura (entre ellos el agarre) permitirá actuar en el proceso de aprendizaje y evitar posibles lesiones o dolores musculares (Condemarín, 1995). Para lograrlo cada equipo docente adopta de manera intencional técnicas y estrategias; sin embargo, en algunas ocasiones, las "buenas intenciones" de las familias son diametralmente opuestas a las establecidas desde el centro. Por ello, González-Vázquez (1012) plantea que la familia y la escuela deben compartir información que permita mantener una línea de coherencia en el feedback proporcionado al niño. Hay que destacar la importancia de seguir una misma línea de actuación con las familias (Urra \& Urra, 2015) y los procesos de autoevaluación en los que se inicia al alumnado (D 122/2007). Toda esta retroalimentación nos adentra en los beneficiosos procesos de evaluación formativa y en la posibilidad de llevarlos a cabo en esta etapa (Castro, Casado \& Pérez-Pueyo, 2017). 


\section{Contextualización}

Esta experiencia se ha llevado a cabo en un Centro Rural Agrupado de la comarca de El Bierzo, en León. En un aula mixta de EI y $1^{\circ}$ y $2^{\circ}$ de Educación Primaria con un total de 7 alumnos, aunque los que nos ocupan en este trabajo son los dos alumnos de 3 años y, por supuesto sus familias. Existían diferencias significativas al inicio del curso pues la niña había acudido anteriormente a la guardería, por lo que mucho del camino ya estaba andado, mientras que el niño no.

\section{Diseño y desarrollo}

El agarre correcto del lápiz ayuda al niño a tener una escritura correcta y una presión sobre él adecuada, ya que al principio agarran con mucha fuerza sin controlar la presión que hacen sobre el lápiz y sobre el papel, aunque como señala Berruelo (1990), sólo es cuestión de tiempo. En este mismo sentido, también es importante la posición de los dedos sobre el lápiz, sin embargo, al ser habituales los procesos de imitación en el aprendizaje, y más en estas edades, en muchos casos algunos adultos no solemos ser un buen ejemplo de cómo se debe coger el lápiz. Por ello, al inicio del curso, se comenta a las familias cómo se va produciendo en el niño este proceso de aprendizaje y cómo pueden colaborar (pero no interferir) y se les facilita un instrumento de evaluación que les permita observar y valorar en casa los avances de sus hijos (figura 1 y 2) y, en momentos concretos, poder corregir situaciones anómalas (figura 3 y 4). Al entregar esta tabla a las familias pretendemos asegurarnos trabajar todos en la misma línea.

Este mismo instrumento (lista de control) se utiliza en el aula para que los alumnos puedan realizar procesos sencillos de autoevaluación, puesto que las fotos les permiten comprobar cómo hacen el agarre desde los diferentes aspectos a valorar.

\begin{tabular}{|c|l|l|l|l|l|l|}
\hline \multicolumn{5}{|c|}{ Acciones observables } \\
\hline $\begin{array}{c}\text { Agarre del lápiz - Fases } \\
\text { Cilíndrico }\end{array}$ & Pinza Bípode & Pinza Cuadrípode & Pinza Trípode & \\
\hline $\begin{array}{l}\text { La } \\
\text { sujeción } \\
\text { del lápiz } \\
\text { se realiza } \\
\text { con el } \\
\text { puño } \\
\text { cerrado. }\end{array}$ & $\begin{array}{l}\text { El lápiz } \\
\text { se } \\
\text { agarrado } \\
\text { sólo con } \\
\text { el dedo } \\
\text { pulgar y } \\
\text { el dedo } \\
\text { indice. }\end{array}$ & $\begin{array}{l}\text { El dedo índice, } \\
\text { el corazón y el } \\
\text { anular sujetan el } \\
\text { lápiz en línea, y } \\
\text { un dedo debajo } \\
\text { de otro haciendo } \\
\text { presión por } \\
\text { detrás con el } \\
\text { pulgar. }\end{array}$ \\
\hline
\end{tabular}

Figura 1.

Fases de agarre del lápiz (Sevilla, Pérez-Pueyo, Suarez \& Vega, 2016). 
los alumnos deben estar vinculados a imágenes y no a texto. En este caso, no debemos fijarnos una fecha concreta para la consecución del logro, ya que cada niño y cada niña tienen un ritmo de desarrollo diferente.

\begin{tabular}{|l|l|}
\hline Acciones observables \\
\hline Punto de agarre del lápiz \\
índice y pulgar) debe encontrarse en el punto en que nuestra mano \\
descansa sobre la superficie en la que se esté trabajando.
\end{tabular}

Figura 4.

Acciones observables del agarre del lápiz (Sevilla, Pérez-Pueyo, Suarez \& Vega, 2016).

La utilización de este instrumento permitirá poner en común con las familias los progresos observados e identificar las diferencias que se produzcan en estos dos contextos (casa-escuela) si se produjesen, intentando encontrar las razones y resolverlas. Aunque no siempre las familias se implican como nos gustaría, en este caso han estado muy dispuestas a colaborar y a ir trabajando en casa siguiendo la pauta marcada por la docente, exponiéndonos los avances o estancamientos.

En cuanto a la diferencia al inicio del curso, por la experiencia previa en Centro de Educación Infantil de uno de ellos, ésta fue compensada a mediados de curso y en ambos casos el agarre del rotulador y posteriormente del lápiz fue el correcto. 


\section{Conclusiones}

La incorporación de la familia y del alumnado a los procesos de evaluación formativa permite hacer al alumnado más conscientes de su propio aprendizaje; aunque lo más importante es la coherencia que el niño percibe en las retroalimentaciones proporcionadas por el docente y sus padres, coherencia que debería ser cotidiana para un desarrollo integral y armónico del alumnado.

En el aula de EI trabajamos diariamente actividades para estimular la motricidad fina. Poner éstas en conocimiento de las familias ayudará a corregir las anomalías en el agarre del lápiz de sus hijos y comprobar los avances. Debemos ayudarle a que sea consciente del agarre correcto por sí mismo y tanto profesores como familia podemos contribuir coordinadamente.

\section{Referencias}

Castro, B., Casado, O., \& Pérez-Pueyo, A. (2017). La evaluación formativa en el aprendizaje de la lectoescritura en educación infantil (pgs 128-129). En V. M. López-Pastor y A. Pérez-Pueyo (coords.) Evaluación formativa y compartida en Educación: experiencias de éxito en todas las etapas educativas. León: Universidad de León.

Condemarín, M., Chadwick, M., \& Milicic, N. (1995). Madurez escolar. Chile: Andrés Bello.

Decreto 122/2007, de 27 de diciembre, por el que se establece el currículo del segundo ciclo de la Educación Infantil en la Comunidad de Castilla y León (BOCyL, 2 de enero de 2008).

García, J., \& Berruezo, P. (2013). Psicomotricidad y Educación Infantil. Madrid: CEPE. Ciencias de la educación preescolar y especial.

González-Vázquez, O. (2012). Familia y escuela / Escuela y familia: Guía para que padres y docentes nos entendamos. Bilbao: Desclee De Brouwer

Ley Orgánica 8/2013, de 9 de diciembre, para la mejora de la calidad educativa (BOE, 10 de diciembre).

Sevilla, A., Pérez-Pueyo, Suarez, B., \& Vega, D. (2016). Escala de valoración y lista de control para el agarre del lápiz (diestros). Recuperada de 
file://C:/Users/Usuario/Downloads/@\%20GRUPO\%20ACTITUDES\%20\%C2\%

$\underline{\mathrm{AE} \% 20-}$

Escala\%20y\%20R\%C3\%BAbrica\%20agarre\%201\%C3\%A1piz\%20diestro.pdf

Sevilla, A., Pérez-Pueyo, Suarez, B., \& Vega, D. (2016). Escala de valoración y lista de control para el agarre del lápiz (zurdos). Recuperada de https://drive.google.com/open?id=0B6zM2sfGO-LsU2UtLU9BZ3dDTmc

Urra, J., \& Urra, B. (2015). Padres en conflicto con sus hijos. Revista del consejo escolar del estado. Las relaciones entre familia y escuela. Ministerio de Educación, Cultura y Deporte, 7(4), 75-79. 